\title{
Challenges for Preventive Digital Stress Management Systems - Identifying Requirements by Conducting Qualitative Interviews
}

\author{
Kim Janine Blankenhagel \\ Technische Universität Berlin \\ k.blankenhagel@tu-berlin.de \\ Anne-Katrin Witte \\ Technische Universität Berlin \\ a.witte@tu-berlin.de
}

\author{
Max-Marcel Theilig \\ Technische Universität Berlin \\ m.theilig@tu-berlin.de \\ Rüdiger Zarnekow \\ Technische Universität Berlin \\ ruediger.zarnekow@tu-berlin.de
}

\author{
Hannah Koch \\ Technische Universität Berlin \\ h.koch@tu-berlin.de
}

\begin{abstract}
Personal health depends on physical factors as well as on the subject's behavior and lifestyle. Stress is the cause of numerous diseases unless it is in balance with sufficient relaxation and rest. Nowadays, continuous stress and, as a consequence, a burnout are steadily increasing, thus the need for prevention and stress management is growing too. Digital technologies allow for new methods of stress management to prevent burnout. However, the requirements for such systems remain largely unexplored. This work closes this research gap by offering a qualitative requirement survey and its analysis. For this purpose, 15 semi-structured interviews were conducted from four different perspectives (health insurance companies, care providers, private sector and users), which allowed to derive the requirements for successful digital stress management systems. These can be divided into three categories: Human Centricity, Medicine and Technology.
\end{abstract}

\section{Introduction}

The diagnosis of burnout is on the rise due to the increased stress levels and the growing complexity in the professional context [13]. Burnout is a subcategory of depression in response to work-related stressors and manifests as a chronic syndrome of fatigue, cynicism, and reduced performance [9]. Preliminary stages are the increased stress levels and work overload in the professional context that lead to new challenges. According to estimates of the World Health Organization, mental illness will be one of the leading causes of disease in industrialized countries by 2030 [16]. Participation in conventional preventive services is low, while the technological capability to mine, interpret and respond to a big amount of data for promoting the welfare of human subjects grows [14]. According to a study by Bitkom, 69\% of all participants believe that digital technologies will improve prevention [2]. Therefore, research continues to focus the use of digital technologies.

In addition to adequate physical exercise, the ability to cope with stress is one of the most important factors for preventing burnout [15]. The term preventive digital stress management systems (DSMS), as defined in this article, covers coping strategies for the preservation of mental, physical and social health. The aim is to reduce stress due to workrelated pressure and help find a healthy balance. As understood here, DSMS are provided mainly in digital form (derived from [8]).

So far, the area of digital prevention of mental illness and the relevant aspects for the DSMS to be successful are largely unexplored [3]. Since the body of knowledge lacks assessments, interpretation patterns and action orientations as well as the identification of individual perspectives, qualitative interviews appear to be a suitable methodology to identify these requirements. In this contribution, interviews were systematically conducted and analyzed regarding the requirements for the development of a successful DSMS for the prevention of burnout. There are some DSMS on the market (e.g. VTON, Selfapy, 7mind) and there are also first studies that address the issues of effectiveness and moderating factors $[1,6,10]$. However, these studies address mainly the medical aspects, whereas this article aims to develop a holistic view and also addresses the user and his needs, as well as some technical aspects. Furthermore, different perspectives are included and compared, which differentiates this paper from existing studies. 


\section{Methods}

In order to set the requirements for DSMS for the prevention of burnout, 15 semi-structured, guidelinebased interviews were conducted in the spring of 2018. To better understand the specificity of the application of DSMS, these were examined and represent the perspective of four key stakeholders: health insurance companies $(\mathrm{n}=3)$, care providers (psychotherapists, medical professionals; $n=4$ ), private sector (providers of DSMS on the open market; $n=4)$ and users $(n=4)$. The final selection of the four groups is based on a comprehensive pre assessment process. Potentially relevant stakeholders were prioritized with regard to burnout and the significance for the German health system. While health insurance companies may not play an equal role in other countries, Germany has a powerful health system and prevention programs for burnout are offered and financed by health insurance companies. In total 25 interview requests were sent by mail and one in form of a request on a quantified-self online forum. In sum, ten telephone and five personal interviews were conducted in German language. The research process including the interviews was selfevaluated regarding human ethics prior to the start.

The interview partners were selected according to Flick [7] following the case selection using a qualitative sampling plan in order to include a targeted selection of particularly meaningful cases. Specifically, the potential interviewees were recruited regarding their professional background and experience in the area of burnout prevention and in the use of digital technologies for stress management (at least 2 years). Depending on the target group, the prerequisite for participation in the interview was either the use (user / care provider) or the offer (private sector / health insurance) of at least one DSMS. On average, an interview took 53 minutes, with the shortest lasting 38 and the longest one 95 minutes. At the beginning of each interview, the interviewer was introduced and the research project, the objective and the structure of the interview was explained. With the consent of each interviewee, the interviews were recorded and subsequently transcribed. The analysis of the interviews was carried out following the principles of the qualitative content analysis according to Mayring [12] with a software for qualitative analysis (MaxQDA). The requirements identified from the interviews were aggregated, coded and analyzed.

\subsection{Interview guideline}

The semi-structured interview guideline is based on the principles established by Bortz and Döring [5] and is derived from the literature and adjusted by the experiences from the research team to better fit and fulfill the study purpose. The preliminary considerations regarding the requirements were taken from existing concepts and theories on DSMS and were derived deductively. The interview guide covers three main themes subdivided into further specific questions. First, the interviewer asked questions regarding interviewee's profile and the relevant experiences (see figure 1, a). The narrative prompts have been used to identify the structure, the mode of operation and the interaction with the existing or previously used stress management systems (see figure $1, \mathrm{~b})$. This was followed by the requirement survey (see figure $1, \mathrm{c}$ ).

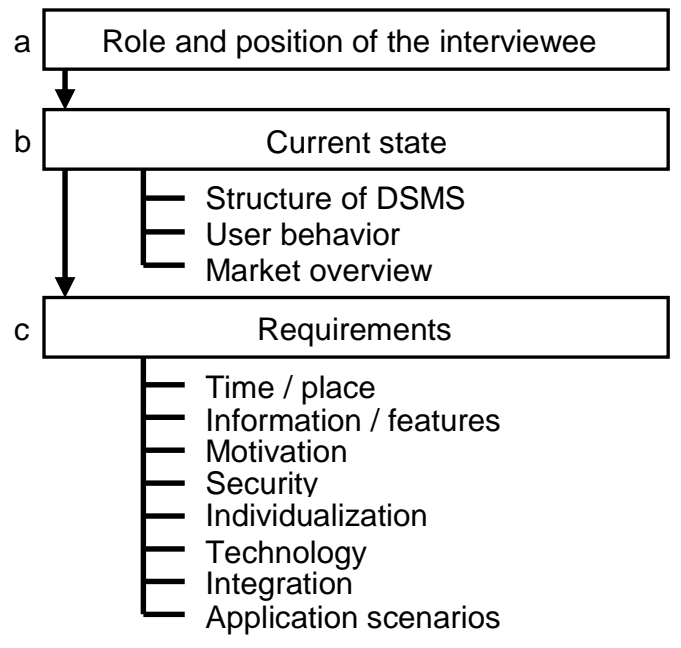

Figure 1. Interview guideline

Since the knowledge and perspectives differ, the interview guideline for each of the four groups was respectively adapted. In general, the questions are formulated according to the principle of openness to give the interviewee an opportunity to respond according to his or her expertise and interests [11]. To ensure that the guideline is appropriate in terms of timing and content, it was individually tested for each group in advance. All interviews were conducted by one researcher.

\subsection{Category system}

The category system was developed rule-based according to Mayring [12]. First, the whole material was viewed and in an iterative process one of the authors inductively developed a category system from four interviews. Furthermore, a coding guide was developed: the characteristics of the individual categories were defined and extended by anchor examples. As a result, the developed categories are disjunct, comprehensive, do not overlap and the subcategories represent characteristics of the respective 
main categories. Only contiguous passages that contained at least three words and a maximum of five sentences were coded. To ensure the intercoder reliability, one of the authors independently encoded part of the interview material a second time. Thus, the interview material was cross-validated and the Cohens Kappa coefficient is 0.85 . After a joint discussion of unclear assignments, the remaining interviews were coded. Figure 2 shows the three resulting categories: Human Centricity (refers to topics that deal with the user as well as human needs and behavior), Medicine and Technology. Additionally, it visualizes the respective subcategories with definitions and anchor examples, which are transformed from their German original into English.

\begin{tabular}{|c|c|}
\hline \multicolumn{2}{|r|}{ Human Centricity } \\
\hline 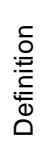 & $\begin{array}{l}\text { all passages referring to the user experience and } \\
\text { the usability of the digital stress management; all } \\
\text { statements that relate to the experiences and } \\
\text { feelings during use; all statements that include } \\
\text { aesthetic and emotional factors }\end{array}$ \\
\hline 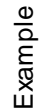 & $\begin{array}{l}\text { "It is important that the user playfully deals with } \\
\text { the content to be learned and the app is } \\
\text { pleasurable to use." }\end{array}$ \\
\hline \multicolumn{2}{|c|}{ Motivation } \\
\hline Фั & $\begin{array}{l}\text { all passages referring to a positive influence on } \\
\text { the behavior of users; all statements on the } \\
\text { motives and motivations of the users (intrinsic } \\
\text { motivation); no statements on user needs } \\
\text { regarding functional requirements }\end{array}$ \\
\hline ن் & "The human component is a huge motivator." \\
\hline \multicolumn{2}{|c|}{ Individualization } \\
\hline 苂 & $\begin{array}{l}\text { all passages referring to the individuality of users } \\
\text { and the system; all statements that relate to } \\
\text { concepts, requirements and specifications; no } \\
\text { statements on the technical implementation of } \\
\text { customization (e.g. by artificial intelligence) }\end{array}$ \\
\hline ن் & $\begin{array}{l}\text { "The betterthe system gets to know me and the } \\
\text { better it knows what makes me feel good, the } \\
\text { more meaningful it is." }\end{array}$ \\
\hline \multicolumn{2}{|c|}{ Interaction } \\
\hline 产 & $\begin{array}{l}\text { all passages referring to the interaction between } \\
\text { the system, the user and other participants; no } \\
\text { statements that directly relate to the interaction } \\
\text { with a physician }\end{array}$ \\
\hline ن் & $\begin{array}{l}\text { "In case of abnormalities, the system should give } \\
\text { constructive hints and exercises." }\end{array}$ \\
\hline Mo & Medicine \\
\hline 产 & $\begin{array}{l}\text { all passages referring to the acquisition, } \\
\text { measurement, observation, monitoring and } \\
\text { logging of certain parameters in the context of } \\
\text { digital stress management }\end{array}$ \\
\hline ن் & $\begin{array}{l}\text { "Stress can be measured by the heart rate } \\
\text { variability." }\end{array}$ \\
\hline
\end{tabular}

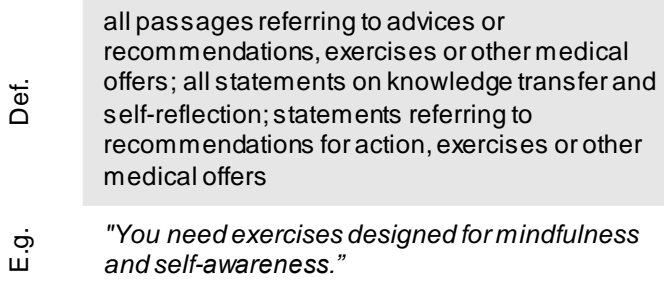

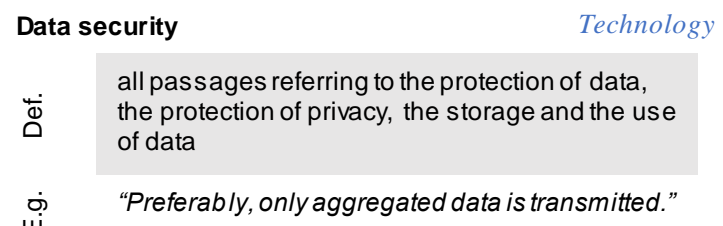

\begin{tabular}{|c|c|}
\hline 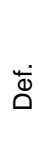 & $\begin{array}{l}\text { all passages referring to the use of collected data } \\
\text { from user behavior, environment and its } \\
\text { documentation bylearning systems; statements } \\
\text { about algorithms, machine learning and } \\
\text { machine-controlled intelligentbehavior }\end{array}$ \\
\hline வ் & $\begin{array}{l}\text { "Perspectively, the use of artificial intelligence } \\
\text { would be great. Thus, you can develop a real } \\
\text { system that creates a profile of the user and gets } \\
\text { to know him more and better and therefore can } \\
\text { give much more precise and more profitable } \\
\text { feedback." }\end{array}$ \\
\hline \multicolumn{2}{|c|}{ Mobility } \\
\hline षे & $\begin{array}{l}\text { all passages referring to the flexible, non-local } \\
\text { and unscheduled use of the system }\end{array}$ \\
\hline ن் & "The app has to work offline as well." \\
\hline \multicolumn{2}{|c|}{ Integration } \\
\hline 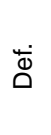 & $\begin{array}{l}\text { all passages referring to the integration of } \\
\text { different sources into one system bas ed on } \\
\text { technical aspects; no statements on human or } \\
\text { social integration }\end{array}$ \\
\hline வ் & $\begin{array}{l}\text { "I miss the compatibility with other applications, } \\
\text { such as my meditation app." }\end{array}$ \\
\hline
\end{tabular}

Artificial Intelligence

Figure 2. Category system 


\section{Results}

The interviews revealed requirements in the areas of Human Centricity, Medicine and Technology. With a share of $57 \%$ and 178 codes, the top category Human Centricity was the most frequently discussed topic across all stakeholder groups. This shows that the needs and desires of users regarding the development of a DSMS for the prevention of burnout are considered as a central feature by the interviewees and should be in the center of attention. Statements on medical requirements $(27 \%, 86$ codes) follow in second place, and the technology category was mentioned with the smallest quantitative share of $16 \%$ and 51 codes. Figure 3 shows the shares of the codes among the groups in total.

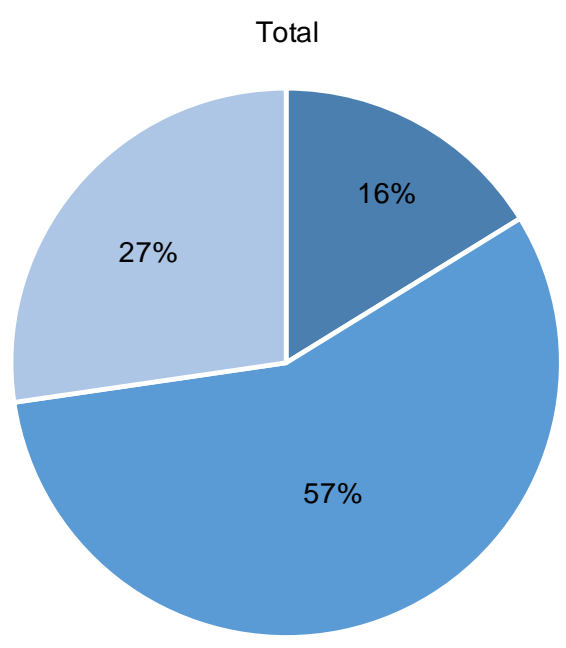

- Technology $\quad$ Human Centricity $\quad$ Medicine

\section{Figure 3. Distribution of the codes in total}

Looking at the distribution within the individual groups, this ranking is reproduced within the health insurance companies, users and care providers. However, in private sector the field of attention is rather related to the technical than to the medical aspects. This, in comparism, little characteristic attached to the medical aspects could be explained by the fact, that currently the private sector is mainly active on the second healthcare market, whereas the questions of medical performance and efficiency will be addressed with greater attention at a later stage of development. In contrast, the development and technical implementation are naturally central issues in the private sector since these technologies and programs are novel. Figure 4 shows the distribution of the codes according to the groups of stakeholders surveyed.

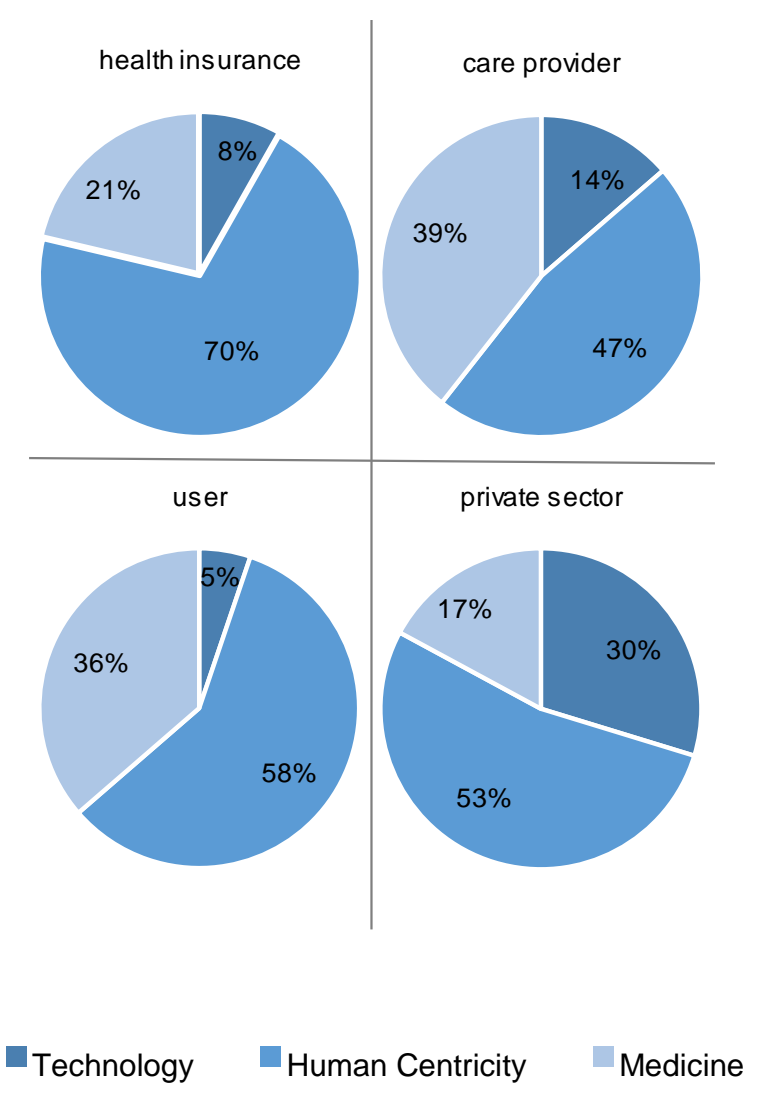

Figure 4. Shares of the codes according to the stakeholders

In the following, the main categories are described in more details. Table 1, at the end of section 3, summarizes all the requirements discussed and indicates how often they are mentioned by each group.

\subsection{Human Centricity}

Within the top category Human Centricity, most coded passages are related to the topics User Experience and Motivation (together 57\%, 102 codes). Both subcategories are closely related in content and, from the point of view of the interviewees, are of particular relevance for the prevention of burnout in contrast to other diseases.

3.1.1. User Experience and Motivation. Healthy people who have a big workload and thus an increased risk of burnout often have little free time and do not possibly feel the symptoms of burnout compared to 
those who are already suffering from it. For this reason, great attention should be paid to the motivational aspects. Particularly, in the field of User Experience and Motivation, providers from the private sector mention a lot of aspects. They explain that the DSMS should incorporate multi-purpose, adaptive, small-scale goals to create positive incentives for the user. A system that generates appropriate behavioral goals from the personal health goals, and thereby having a motivational effect, would be beneficial. One of the interviewed psychotherapists explains the principle behind it: any behavioral change is generally associated with great mental effort. Therefore, if people are stressed, it is helpful if their own goals are regularly clarified and subdivided, so that they can have a feeling of success more frequently. Reminder functions on the goals, open exercises or other interactions with the system are seen as positive features. Additionally, users wish to be able to make individual settings regarding reminder frequencies and functions. Moreover, all respondents believe that processing times of a DSMS should be very short. For instance, the recommended usage times only vary between 5 and 15 minutes per day, in average 8 minutes. These short usage times can be addressed through a quick check-in, a clear structuring and menu guidance as well as a landing page in form of an overview that allows for screening.

The possibility to operate the system simply and intuitively plays a key role since it allows saving time and boosts motivation. The increase in flexibility of time management and the fast pace in the working life nowadays explain the rise of importance of time requirements. People who are under big stress are only willing to do a preventive program if they can operate it in a very short time. In the development of DSMS these factors should be taken into account to address the part of the population that takes less time off-work for interventions and therefore may be facing an increased risk of burnout. Regardless their position, all interviewees also indicate that the use of a DSMS must be fun so that's utilization is sustainable. The word fun occurs in the interviews a total of 14 times and altogether ten interviewees mention it. According to an interviewed psychotherapist, fun always arises when the motive and the goals of an action are well coordinated. This aspect further emphasizes that setting goals has a great motivational effect. Additional characteristics to increase the fun factor avoid the use of technical terms and employ different formats (image, film, text, etc.) with a high personal relevance and a clear reference to everyday life.

The stakeholder group users relate their statements on the topics of User Experience and Motivation mainly to the aspects of everyday usability. Thus it is important for them that appropriate DSMS can be easily integrated into everyday life (for example by using them on a smartphone) or, in the case of integration of external devices, have a high wearing comfort and can be carried on the body inconspicuously. Three of the four interviewed users also state that the used device (smartphone / headband / fitness tracker) has taken on an anchor role and is directly associated with mindfulness and relaxation. Both, the users and the health insurance companies underline that a clear presentation of cause and effect relationships has a highly motivating effect. Accordingly, it would be desirable, for example, after a completed exercise to visualize the reduced stress level and emphasize the causal link.

3.1.2. Individualization. It is noticeable that all interviewees in all included stakeholder groups speak in favor of a high degree of individualization of the DSMS. They wish for a tool that can be tailored to the needs of the users. This could be achieved, for example, by setting options and a personal onboarding, in which the user is asked in detail about his needs and goals and the system adapts accordingly. The individual fit of the DSMS can be realized by employing a software that gets to know the user, identifies his stressors and derives the interventions that help most. This creates a system that responds to the user's current level of stress and supports him with personalized instructions and exercises. Following this line of requirements, it is a necessary condition that the stress level of the user is measured and evaluated as continuously as possible. In addition to tailoring the system to the person, the interviewees also make further demands regarding individual fitting of the system to the environment of the user. In some situations, (such as staying in a particular conference room), it should be possible to disable or individually configure the interaction with the system. Accordingly, instructions and recommendations for action provided to the user can be intelligently controlled and, at appropriate times, adapted to the circumstances of his personal everyday life. A high autonomy as well as a proactive structure of the DSMS and the concomitant increase of the possibility to individualize it are seen as a central requirement for appropriate applications by the interviewees.

In particular, the health insurances and care providers state clearly, that the decisive benefit depends on IT support for the prevention of burnout referring to the possibility to make individual adjustment and incorporate learning systems.

3.1.3. Interaction. The Interaction category is predominantly mentioned by interviewees 
representing the private sector and by the users $(38 \%$ each, 15 codes). Both groups welcome mature feedback features. A DSMS should issue hints or warnings in acute stress situations for reason of identifying individual stressors and counteracting current stress phases. This can reveal negative disbalances between periods of stress and recovery, and help detect early signs of forthcoming burnout. Users explain that this functionality leads to increased awareness and mindfulness. The prerequisite, however, is that the device measuring stress is also worn when stressful situations occur. Furthermore, feedback should be provided by the system on the effect and efficacy of exercises and actions performed. On the one hand, it can set incentives and, on the other hand, show the progress. In addition to the real-time feedback, reports on medium to long-term trends and progressions of stress levels are also required. From the point of view of health insurances and care providers, not only the DSMS and the user should interact with each other but also the inclusion of a human component (for example in the form of chats) is recommended. This mix of digital self-management and human communication leads to significantly lower drop-out rates. In contrast to that, none of the interviewed users explicitly addresses or desires the integration of human components and capabilities into the system.

Instead, they are interested in comparing their own stress level with that of an adequate peer group (for example, people of similar age in the immediate environment). On the other hand, such comparative functions are critically evaluated by care providers. For therapeutic reasons, they consider competitive thinking to be counterproductive in burnout prevention.

\subsection{Medicine}

Within the category Medicine, the subcategories Intervention (47\%, 40 codes) and Monitoring (45\%, 39 codes) dominate. Here the focus is mainly on functional requirements that relate to a more concrete design of DSMS.

3.2.1. Monitoring. Health insurance companies, private sector and care providers require to have diary or documentation functions in which the user can record his stress level and other significant influencing factors and thus be able to identify individual stressors. The users themselves do not express this need. They relate exclusively to functions of stress measurement, such as the continuous measurement of pulse and heart rate variability, respiratory rate or brainwaves. This can be explained by the fact that diary or documentation functions are already available in analogous form or on conventional applications (apps) and as sole functions offer only a limited benefit. Care providers also express their desire for functions that perform voice analysis, measure muscular tension in the neck area and skin resistance.

Stress is very abstract in comparison to other diseases, which makes it more difficult to measure and therefore harder to visualize the success. However, a wide application range of the monitoring tools and functions mentioned in the interviews shows that there are different physical reactions to stress that can be quantified and deliver concrete indications of stress. A standardized procedure to effectively measure stress with biological markers has been missing so far. According to the interviewees, it is important that at least one stress-measuring functionality is integrated into the system (for example wearable devices are suitable for this purpose) and is then transformed into a main metric for the user. This allows the user to observe and analyze when and how frequent he had stressful situations over a longer period of time. At this point it is desirable to provide a detailed drill down possibility. For example, the DSMS should subdivide stress into low, medium and high stress phases or specify the duration of the stress phase. Noteworthy, health insurances are hardly involved in the discussion about stress measurement and currently offer mainly web-based DSMS which are not linked to stress measuring technologies.

The private sector also argues that DSMS should detect deviations from normal behavior. For instance, a change in the user's GPS location (for example, he only stays in the office and hardly ever leaves it) could give the first indications that a disease might occur. Except for the health insurances, all the interviewed stakeholders are in favor of adapting the stressmeasuring monitoring element to the development over time and period of use. At the beginning of usage, it is particularly important that the user deals with his current level of stress regularly and extensively. Therefore, frequent learning opportunities to quantify and evaluate one's own stress level and to identify the stressors have to be offered. Afterwards, medium to long-term trends of stress development move into the spotlight rather than cause-effect relationships and individual situations.

3.2.2. Intervention. The subcategory Intervention is often mentioned by all stakeholder groups. Basically, the requirement is that the interventions should be designed and suited for a healthy population, for people with risk for burnout disease and for people with early symptoms that cannot clearly be related to a disease. One of the therapists adds that the DSMS 
should address cognitive, emotional and muscular levels of stress reduction. The four stakeholder groups interviewed mention various intervention proposals. Commonly, they relate to knowledge transfer, reflection and the development of resources for coping with stress. In particular, care providers emphasize that psychoeducation and education on stress, burnout and prevention can be processed and communicated very well using Internet technologies. The field of selfreflection includes exercises for better body perception (body scan), increased awareness and sensitization as well as self-observation exercises.

The development of resources for coping with stress is subdivided into short-term strategies such as breathing exercises, meditation or brainteasers, which primarily serve stress relief. Long-term strategies such as resource analysis, time management, or possible changes of the mind set or behavioral patterns should improve the balance of stress periods and recreation. The care providers and health insurances emphasize that any interventions should be scientifically proven.

Furthermore, they plead for fundamental deceleration in processing interventions by the user. Stress-prone people tend to finish a program as quickly as possible, without letting the exercises and cues take effect. Therefore, it is recommended to enforce this certain deceleration by enabling actions only after certain events, repetitions or time intervals.

3.2.3. Interaction physician. The possibility to involve a doctor, a psychotherapist or other medical professional is assessed positive and desirable by all interviewees. However, this aspect is hardly discussed among the private sector. The users would like to be able to contact a doctor in case their condition deteriorates or to be able to show the evaluations to their family doctor. Thus, it is necessary that the work done with the DSMS can be printed out in a compact form and key facts are well presented for a physician. In this case, the therapists also consider it useful to include the results of a corresponding system in the diagnosis, counseling or even a therapy. Two of the three health insurances interviewed wish for additional staff who would offer counselling on coping with stress. This staff, if needed, could also be contacted by the users and is trained to provide incentives and assistance.

\subsection{Technology}

With $16 \%$ and 51 coded text passages, the Technology category is the least discussed category in terms of quantity. In sum, it is characterized by statements from the private sector for which data protection issues are at the center of attention. In addition, artificial intelligence, compatibility with other applications and mobility aspects are addressed.

3.3.1. Data security. Basically, all interviewees demand a profound data protection concept including high security and high protection of the data. Statements by representatives of the private sector are at this point more detailed. For example, they suggest that applications should be completely encapsulated. Thus, it should be displayed on a smartphone (including data processing), while the data does not even have to be transferred. If data transmission is necessary, however, it is desirable to completely anonymize the data and transmit it in aggregated form.

The users must be comprehensively informed about the underlying data protection concept so that there is consensus on the purpose-based use of the data. Furthermore, the user should be able to access his own raw data material in a machine-readable and structured format or to delete it. The private sector emphasizes that all collected data belongs to the user himself and that he can decide, both technically and legally, what should happen to it. Therefore, following the demand of the users, functions should be provided to share the data with other people (e.g. doctors, healthcare professionals or friends). The care providers, users and health insurances also associate great priority to the safe handling of the personal data.

3.3.2. Artificial Intelligence. In the category Human Centricity with the subcategory Individualization described above, all interviewees stated that individual tailoring is a crucial requirement. The care providers and the private sector continue to specify in which way such an individual DSMS could be technically implemented. At this point, preference is given to learning systems based on artificial intelligence. Based on algorithms, software that learns the profile and characteristics of the user over time results in a highly individualized stress management tool. Building on it, meaningful feedback and interactions help detect deviations from the normal pattern. Automatic detection of voice and mood changes as well as the recommendation of interventions and other influencing factors that have positive effects on the stress level are among the functionalities that artificial intelligence should provide.

Care providers emphasize that there is a very individual development behind every burden of stress or work-related depression, which is not taken into account by non-individualized DSMS. Therefore, special attention should be paid to Individualization and Artificial Intelligence. This is also reflected in the interviews: with a total of 44 codes, Individualization 
and Artificial Intelligence are the three most frequently mentioned topics.

3.3.3. Mobility and Integration. All interviewees also plead in favor of a high degree of mobility. Thus, the DSMS should ideally be accessible on a smartphone or other device, which is carried every day and can be used any time. Apps offer advantages over web pages, and all stakeholders who work exclusively with web- based systems, are already working on a mobile version or recognize the need to have one. Furthermore, a higher flexibility can be achieved if the respective application is available offline. Apart from the health insurances, the interviewees also discuss good compatibility with other applications and the corresponding integrability. In particular, users welcome the possibility to integrate data and results from other apps (e.g. pedometer) into their prevention system and join selected elements.

\section{Table 1. Raised requirements for DSMS according to their frequency}

\begin{tabular}{|c|c|c|c|c|c|}
\hline \multicolumn{2}{|r|}{ Requirements } & $\begin{array}{c}\text { Health } \\
\text { Insurance }\end{array}$ & $\begin{array}{c}\text { Care } \\
\text { Provider }\end{array}$ & User & $\begin{array}{l}\text { Private } \\
\text { Sector }\end{array}$ \\
\hline \multirow{15}{*}{ 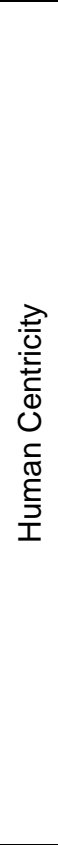 } & $\begin{array}{l}\text { Consecutive, adaptive, small-step goals; behavioral goals } \\
\text { are derived from health goals }\end{array}$ & & & & \\
\hline & $\begin{array}{l}\text { Reminder functions to goals, open exercises or other } \\
\text { mature interactions; individually configurable }\end{array}$ & & & & \\
\hline & $\begin{array}{l}\text { Short interaction times (about 5-15 minutes per day); quick } \\
\text { check-in, clear structure and menu navigation, overviews }\end{array}$ & & & & \\
\hline & Simple and intuitive usability, fun to use & & & & \\
\hline & Hidden content, only few technical terms & & & & \\
\hline & High personal and clear everyday relevance & & & & \\
\hline & Everyday suitability and high wearing comfort & & & & \\
\hline & Clear presentation of cause and effect relationships & & & & \\
\hline & $\begin{array}{l}\text { High individualization including personal on-boarding, } \\
\text { individual configuration options and tailoring to the user }\end{array}$ & & & & \\
\hline & $\begin{array}{l}\text { Support to identify stressors and derive appropriate } \\
\text { measures }\end{array}$ & & & & \\
\hline & Measurement of stress level & & & & \\
\hline & Customization to the specific user situation & & & & \\
\hline & High autonomy; proactive construction & & & & \\
\hline & $\begin{array}{l}\text { Feedback functions in acute stress situations and } \\
\text { effectiveness of implemented measures and exercises; } \\
\text { Reports on medium to long-term trends in stress levels }\end{array}$ & & & & \\
\hline & Inclusion of human components & & & & \\
\hline \multirow{12}{*}{ 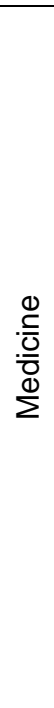 } & Diary or documentation function & & & & \\
\hline & $\begin{array}{l}\text { Continuous measurements of heart rate variability and } \\
\text { respiratory rate }\end{array}$ & & & & \\
\hline & $\begin{array}{l}\text { Analysis of vocal pitch, muscular tension in the neck area } \\
\text { and skin resistance }\end{array}$ & & & & \\
\hline & $\begin{array}{l}\text { At least one stress-measuring functionality is available and } \\
\text { transformed into an understandable main metric; detailed } \\
\text { drill down capabilities for stress levels }\end{array}$ & & & & \\
\hline & Detection of deviations from the normal pattern & & & & \\
\hline & Adaption of stress monitoring over time & & & & \\
\hline & $\begin{array}{l}\text { Interventions include exercises in psychological self- } \\
\text { education }\end{array}$ & & & & \\
\hline & Interventions include exercises for self-reflection & & & & \\
\hline & $\begin{array}{l}\text { Interventions include exercises to build up anti-stress } \\
\text { resources }\end{array}$ & & & & \\
\hline & Interventions are scientifically driven & & & \pm & 1 \\
\hline & $\begin{array}{l}\text { Possibility of integration of a doctor, psychotherapist or } \\
\text { medical professional }\end{array}$ & & & & \\
\hline & Adequate overview function for a supervising physician & & & & \\
\hline
\end{tabular}




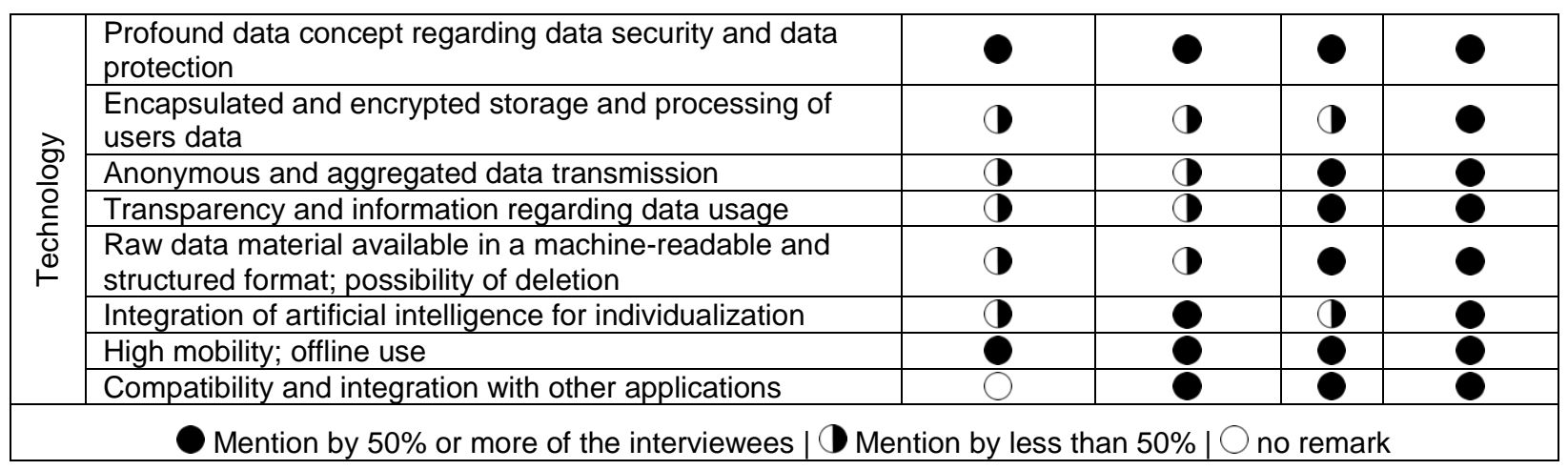

\section{Discussion}

This study revealed various requirements in three areas. Regarding Human Centricity, it is of particular importance that DSMS can adapt individually and are flexible in terms of time and place which ensures that they are actively used every day. In addition, strong motivational elements such as short processing times, clear benefits and reminder functions are important.

From a medical point of view, the interviews showed that the key requirement of DSMS is to measure stress. Despite the unspecific manifestation of stress, various options how to make stress measurable on a physical level were discussed. These include, for example, the measurements of heart rate variability, respiratory rate, skin resistance or muscular tension. Interventions based on the measured level of stress should have a scientific basis and include elements of knowledge transfer, short-term relief of stress symptoms, and means to establish a balance between stress and relaxation over a long period of time.

From a technical point of view, compliance with a high standard of data protection is of fundamental importance. The use of artificial intelligence and selflearning systems to better customize the DSMS is seen as the key added value for the use of technology in prevention. This promises even further advantages in the future which are hardly to describe as of today. In sum, for the prevention of burnout the DSMS need to have some special features that are addressed in the requirements and are not transferable to other mental illnesses. For instance, DSMS should prioritize elements of deceleration and calmness to give stressed people an opportunity to consciously switch off from the fast-paced lifestyle of their day-to-day work. At the same time, the actual interaction time users spent on working with the system should be kept short in order to reduce the dropout rates and to encourage users to focus on body and mind.

While some of these aspects have already been partially discussed in previous research $[6,10]$ in this article a comprehensive set of requirements, derived from interviews from different stakeholder perspectives, was collected and categorized. Similar studies investigate the usage of DSMS in the workplace itself. In comparison to the existing study, it is striking that some of the requirements raised, such as high mobility or anonymity, may require adjustments in the working environment. The compliance with anonymity is possible if the DSMS is used outside the office. However, if a DSMS is used at work, the process is visible to colleagues or supervisors and therefore no longer anonymous. Supplementary, the requirement for high mobility can also have disadvantages at the workplace, as there may be difficulties in prioritizing time and separating work and therapy [4].

Overall, in the context of this survey many nonfunctional requirements were collected. Therefore, it can be concluded, that aspects of user-friendliness and the way of implementation are of great importance.

\subsection{Limitations}

It is inherent that single initial explorative interviews can lead to interpretational differences and subjective influences due to the personal experiences and knowledge of the authors. Further limitations of the research work are seen in the selection of interviewees. Since these were specifically recruited according to their professional experience in that area, unilaterally distorted requirements could have been raised, in particular when questioning the users. Due to their latent biased interest in DSMS, their perspectives and views might not be generalizable. Additionally, the results are derived from a German peer group in a health care context that is highly influenced by the German and European medical system and regulations. Therefore, generalizing the results to non-European countries is only implicit. The biggest part of the interviews was conducted by telephone, which by the nature of things makes it difficult to account for standardization. 


\subsection{Conclusion}

The analysis of the interview data helped to confirm that, in general, there is a belief that digital stress prevention may contribute to the healthcare supply. The interpretation of the opinions presented in the interviews shows that there is an interplay of medicine and technology, which has reinforcing synergy effects if certain requirements and characteristics are considered.

\subsection{Future Work}

Future research should focus on quantitative validation and prioritization of the collected requirements. An equivalent DSMS which meets all requested requirements could cause a high complexity and could be very expensive. Taking this information into consideration, it is essential to run comprehensive validations to evaluate the upcoming costs and the needed equipment. Additionally, the involvement of employers as a further stakeholder group would be of interest because they are closely related to the stresscausing source of burnout.

\section{References}

[1] D.W. Billings, R.F. Cook, A. Hendrickson, and D.C. Dove, "A web-based approach to managing stress and mood disorders in the workforce", Journal of Occupational and Environmental Medicine, 50(8), 2008, pp. 960-968.

[2] Bitkom, "Welche der folgenden Aussagen zu digitaler Medizin treffen Ihrer Meinung nach zu?", Retrieved from https://de.statista.com/statistik/daten/studie/ 695266/umfrage/pharmaumfrage-zu-vorteilen-vondigitaler-medizin/, 2018.

[3] K.J. Blankenhagel and R. Zarnekow, "Digitalisierung in der psychotherapeutischen Versorgung - ein LiteraturReview zum Status quo internet- und mobilbasierter Versorgungsprogramme und Ableitung einer Klassifizierung", Proceedings of the Multikonferenz der Wirtschaftsinformatik, Lüneburg, Germany, 2018, pp. 683-694.

[4] S. Carolan, R.O. de Visser, "Employees' Perspectives on the Facilitators and Barriers to Engaging With Digital Mental Health Interventions in the Workplace: Qualitative Study", JMIR Mental Health 5(1), 2018, p.1

[5] Döring, N., and Bortz, J., Forschungsmethoden und Evaluation in den Sozial- und Humanwissenschaften, Springer, Berlin, Heidelberg, 2016.
[6] D.D. Ebert, D. Lehr, E. Heber, H. Riper, P. Cuijpers, and M. Berking, "Internet- and mobile-based stress management for employees with adherence-focused guidance. Efficacy and mechanism of change", Scandinavian Journal of Work, Environment \& Health, 42(5), 2016, pp. 382-394.

[7] Flick, U., Qualitative Sozialforschung. Eine Einführung, Rowohlts Enzyklopädie im Rowohlt Taschenbuch Verlag, Reinbek bei Hamburg, 2017.

[8] A. Günthner and A. Batra, "Stressmanagement als Burn-out-Prophylaxe", Bundesgesundheitsblatt Gesundheitsforschung - Gesundheitsschutz, 55(2), 2012, pp. 183-189.

[9] J.J. Hakanen, A.B. Bakker, "Born and bred to burn out. A life-course view and reflections on job burnout", Journal of Occupational Health Psychology, 22(3), 2017, pp. 354-364.

[10] E. Heber, D. Lehr, D.D. Ebert, M. Berking, and H. Riper, "Web-Based and Mobile Stress Management Intervention for Employees. A Randomized Controlled Trial", Journal of Medical Internet Research, 18(1), 2016.

[11] Lamnek, S., and Krell, C, Qualitative Sozialforschung, Beltz, Weinheim, Basel, 2016.

[12] Mayring, P., Qualitative Inhaltsanalyse. Grundlagen und Techniken, Beltz, Weinheim, Basel, 2010.

[13] H. Möltner, J. Leve, and T. Esch, "Burnout-Prävention und mobile Achtsamkeit. Evaluation eines appbasierten Gesundheitstrainings bei Berufstätigen", Gesundheitswesen, 80(3), 2018, pp. 295-300.

[14] A.R. Pisani, P.A. Wyman, D.C. Mohr, T. Perrino, C. Gallo, J. Villamar, K. Kendziora, G.W. Howe, Z. Sloboda, and C.H. Brown, "Human Subjects Protection and Technology in Prevention Science: Selected Opportunities and Challenges", The Official Journal of the Society for Prevention Research, 17(6), 2016, pp. 765-778.

[15] U. Walter, C.S. Krugmann, and M. Plaumann, "Burnout wirksam prävenieren? Ein systematischer Review zur Effektivität individuumbezogener und kombinierter Ansätze", Bundesgesundheitsblatt Gesundheitsforschung - Gesundheitsschutz, 55(2), 2012, pp. 172-182.

[16] H.U. Wittchen, F. Jacobi, J. Rehm, A. Gustavsson, M. Svensson, B. Jönsson, J. Olesen, C. Allgulander, J. Alonso, C. Faravelli, L. Fratiglioni, P. Jennum, R. Lieb, A. Maercker, J. van Os, M. Preisig, L. Salvador-Carulla, R. Simon, and H.C. Steinhausen, "The size and burden of mental disorders and other disorders of the brain in Europe 2010", Journal of the European College of Neuropsychopharmacology, 21(9), 2011, pp. 655-679. 